\title{
CT-guided microwave ablation through the lungs for treating liver tumors near the diaphragm
}

\author{
Han $\mathbf{Q i}^{1,{ }^{1}}$, Hao Zhang ${ }^{2, *}$, Chao Wan ${ }^{1, *}$, Lin Xie ${ }^{1}$, Ze Song ${ }^{1}$ and Weijun Fan ${ }^{1}$ \\ ${ }^{1}$ Department of Imaging and Interventional Radiology, Sun Yat-sen University Cancer Center, State Key Laboratory of \\ Oncology in South China, Collaborative Innovation Center of Cancer Medicine, Guangzhou, China \\ ${ }^{2}$ Department of Interventional Medical Center, The Affiliated Hospital of Qingdao University, Qingdao, China \\ *These authors have contributed equally to this work \\ Correspondence to:Weijun Fan, email: fanwj@sysucc.org.cn
}

Keywords: CT-guidance, microwave ablation, liver tumor, diaphragm, treatment

Abbreviations: MWA: microwave ablation; CR: complete response; ICR: incomplete response; LR: local recurrence; KPS: Karnofsky Scal

Received: October 24, 2016

Accepted: March 20, 2017

Published: April 26, 2017

Copyright: Qi et al. This is an open-access article distributed under the terms of the Creative Commons Attribution License 3.0 (CC BY 3.0), which permits unrestricted use, distribution, and reproduction in any medium, provided the original author and source are credited.

\section{ABSTRACT}

Purpose: To explore the short-term efficacy and safety of CT-guided microwave ablation (MWA) for treating liver tumors near the diaphragm.

Results: The complete response (CR) rate for CT-guided MWA through the lung was $94.7 \%(124 / 131)$. The incomplete response (ICR) rate was $5.3 \%(7 / 131)$, of which 6 patients with ICRs achieved CRs after MWA. The CR rate for Group I was higher than Group II $(99.0 \%$ vs. $80.0 \%, P=0.001)$. The mean follow-up time was $11.2 \pm 7.50$ months. The total local recurrence (LR) rate was $15.3 \%(20 / 131)$. The complication rate was $\mathbf{2 6 . 5 \%}$, and no severe complications were recorded. All complications were controllable and treatable. The incidence of diaphragmatic thickening during the MWA was $18.8 \%(P>0.05)$; the incidence of exudative changes inside the lungs was $6.8 \%(P>0.05)$.

Conclusions: CT-guided MWA can detect changes in liver tissue, in the diaphragm and nearby lung tissues during the ablation process. It's safe and effective to treat tumors close to the diaphragm by CT-guided MWA through the lung.

Methods: CT-guided MWA was used on 131 tumors that were close to the diaphragm (distance between tumor and diaphragm $\leq 5 \mathrm{~mm}$ ) in 117 patients with liver cancer. The tumors were divided into a $<3.0 \mathrm{~cm}$ group (Group $I, n=101$ ) and $a \geq 3.0 \mathrm{~cm}$ group (Group II, $\mathrm{n}=\mathbf{3 0}$ ) based on tumor diameters. The complications within 2 weeks following treatment were counted, and the safety and short-term efficacy of MWA were analyzed.

\section{INTRODUCTION}

Image-guided thermal ablation therapy has become the standard treatment for small liver tumors [1-4]. Ultrasoundguided percutaneous microwave ablation (MWA) has been widely applied for liver tumor treatment due to ease of operation and real-time monitoring; [5-8] however, because ultrasound is usually impacted by pulmonary gas and ribs, it is hard to have a clear display for liver tumors close to the diaphragm [9-12]. Artificial pleural effusion and artificial ascites help to solve the problem in part, but both techniques have their own limitations. For tumors close to the diaphragm, CT imaging has high resolution and accurate positioning $[13,14]$. Thus, CT-guided MWA can optimize the needle track for the best effect. It is often necessary to puncture through the lung tissues to reach the liver tumors accurately. The therapeutic efficacy of MWA through lung tissues for treating liver tumors close to the diaphragm is a matter of debate. In addition, whether or not there are more complications and whether or not the size of the tumors 
Table 1: Grouped complications according to tumor size

\begin{tabular}{|c|c|c|c|c|}
\hline \multirow{2}{*}{ Complications } & \multicolumn{2}{|c|}{ Grouped According to Tumor Size } & \multirow{2}{*}{$\chi^{2}$} & \multirow{2}{*}{$\boldsymbol{P}$} \\
\hline & Group I (101) & Group II (30) & & \\
\hline Mild pulmonary bleeding & 2 & - & & \\
\hline Mild right pneumothorax & 12 & 8 & 3.909 & 0.048 \\
\hline Mild right pleural effusion & 4 & 2 & 0.388 & 0.620 \\
\hline $\begin{array}{l}\text { Mild hepatic subscapular } \\
\text { bleeding }\end{array}$ & 2 & 1 & 0.189 & 1.000 \\
\hline Total & 20 & 11 & 3.642 & 0.085 \\
\hline
\end{tabular}

The tumors were sorted to Group I if the size of the tumor was $<3.0 \mathrm{~cm}$ and the tumors were sorted to Group II if the size of the tumor was $\geq 3.0 \mathrm{~cm}$.

affects the MWA results and complication rate have not been established. Currently, there is no literature on these perspectives. To evaluate the short-term efficacy and safety of CT-guided MWA, we retrospectively studied 131 liver tumors close to the diaphragm in 117 patients.

\section{RESULTS}

\section{Therapeutic efficacy}

CT-guided MWA through the lung was successfully carried out on all 131 liver tumors close to the diaphragm in 117 patients. The average MWA power was $60.4 \pm 6.8$ watt (range: 50-80 watt), and the average MWA time was $9.5 \pm 3.3 \mathrm{~min}$ (range:3-30min). The CR rate 1 month after MWA was $94.7 \%(124 / 131)$. The ICR rate was $5.3 \%$ (7/131), of which 6 patients with residual lesions achieved $\mathrm{CR}$ after complementary MWA. One patient had an active residue at the lesion edge, but declined further treatment, and the tumor shrank in the subsequent follow-up. The CR rates for Groups I and II were 99.0\% (100/101) and 80.0\% (24/30), respectively. The CR rate for Group I was greater than Group II $(\chi 2=16.525, \mathrm{P}=0.001)$.

The total LR rate was $15.3 \%(20 / 131)$. The LR rate for Groups I and II were 12.9\% (13/101) and 23.3\% (7/30), respectively; there was no statistical difference between the two group $(\chi 2=1.957, \mathrm{P}=0.245)$. The median follow-up time was 11.0 months (average, 11.2 months \pm 7.49; range, 1-36 months).

\section{Complications}

The total complication rate was $23.6 \%$ (31/131), including 20 patients with mild right-sided pneumothoraces $(15.3 \%), 6$ patients with mild right-sided pleural effusions (4.6\%), 3 patients with mild hepatic subscapular bleeding $(2.3 \%)$ and 2 patients with mild pulmonary bleeding (1.5\%). The total complication rate for Group II was higher than group I ( $43.3 \%$ vs. $19.8 \%, \chi^{2}=6.796, P=0.015$; Table 1). In subgroup analysis, the incidence of pneumothoraces of Group II was also higher than Group I. There were no treatment-related deaths or disabilities.

\section{Stress response}

There were 22 patients (18.8\%) with diaphragmatic thickening occurred during MWA. There were 8 patients $(6.8 \%)$ with pulmonary exudative changes. With respect to Groups I and II, the diaphragmatic thickening rates were $13.9 \%$ and $26.7 \%\left(\chi^{2}=2.714, P=0.161\right)$, respectively, and the pulmonary exudation rates were $5.0 \%$ and $10.0 \%$ $\left(\chi^{2}=1.029, P=0.383\right)$, respectively.

\section{DISCUSSION}

With the development of image-guided thermal ablation technology, MWA and radiofrequency ablation (RFA) have been increasingly used to treat liver cancers [1-4]. The short- and long-term therapeutic efficacy of thermal ablation is comparable to surgery in liver cancer [15]. Compared to RFA, MWA has unique advantages. Specifically, MWA has the following advantages: a fast heat generation, high intratumoral temperature, short ablation time and large ablation range. MWA is an open system which does not need an extracorporeal electrode plate. Furthermore, MWA has a strong ability to penetrate tissues with high frequency and the effect is synergistic combined with multiple antennas. MWA is less affected by carbonization and blood perfusion flow. In contrast, RFA is a closed system that requires an extracorporeal electrode plate to form a closed-loop, leading to a low intra-tumoral temperature, a long ablation time, and a small ablation range. Compared to RFA, the single antenna MWA can be applied for treating larger tumors. The single antenna MWA reduces the number of punctures required, leading to a decreased incidence of complications. Currently, the most commonly used image-guided technologies including ultrasound, CT, and MRI [16], of which ultrasound guidance is most widely used due to the advantage of real-time monitoring and simple operation [5-8]. For liver cancer near the diaphragm, especially near the top of the diaphragm, the ultrasounds works poorly, and sometimes cannot display the tumor due to the impact of pulmonary gas and ribs [9-12]. Note that, in our study a 68-year-old male received ultrasound-guided MWA for liver S8 cancer 
with a diameter of $1.2 \mathrm{~cm}$ in another hospital. A 1-month follow-up showed that the lesions were still located in the original position, and a low-density ablation lesion appeared adjacent to the original liver cancer (Figure 1). A 57-yearold female underwent ultrasound-guided MWA for a liver $\mathrm{S} 8$ metastatic tumor with a diameter of $1.8 \mathrm{~cm}$. The postoperative review showed that a small portion of the lesion was ablated (Figure 2). These two cases had a history of an "off-target" phenomenon after ultrasound-guided MWA outside our hospital. CT-guided MWAs were successfully implemented in our hospital, and the lateral review showed that the liver tumors were completely ablated.

Clear displays of tumor and puncture path are the most important conditions for MWA. With the advent of artificial pleural effusion [17] and artificial ascites [18], ultrasound-guided MWA for liver tumors near the diaphragm has become possible [19-21]. Song et al. [20] retrospectively analyzed 143 patients with $148 \mathrm{HCC}$ lesions with a diameter $<4 \mathrm{~cm}$ near the diaphragm, and the CR rate was $85.3 \%$, which was significantly lower than our study. Park et al. [21] retrospectively analyzed 116 liver tumors with diameters $<3 \mathrm{~cm}$, of which 56 were near the diaphragm. The CR rate was $87.5 \%$, which was significantly lower than our study, and even lower than the $99.0 \%$ in the group of liver tumor diameters with $\mathrm{a}<3 \mathrm{~cm}$. Nam et al. [22] analyzed 28 HCC lesions with diameters $<$ $5 \mathrm{~cm}$ near the diaphragm, and the LR rate of the artificial ascites-assisted $(n=15)$ and control groups $(n=13)$ was $26.7 \%$ and $23.1 \%$, which were both higher than our study. With respect to ultrasound-guided WMA for an artificial pleural effusion, Koda et al. [19] retrospectively analyzed 23 patients with $\mathrm{HCC}$ lesions with a diameter $<5 \mathrm{~cm}$ near the top of diaphragm and the CR rate was $88.0 \%$, which was significantly lower than our study. Zhang et al. [23] retrospectively analyzed $31 \mathrm{HCC}$ lesions with diameters $<5 \mathrm{~cm}$ near the diaphragm, and the LR rate was $16.1 \%$,
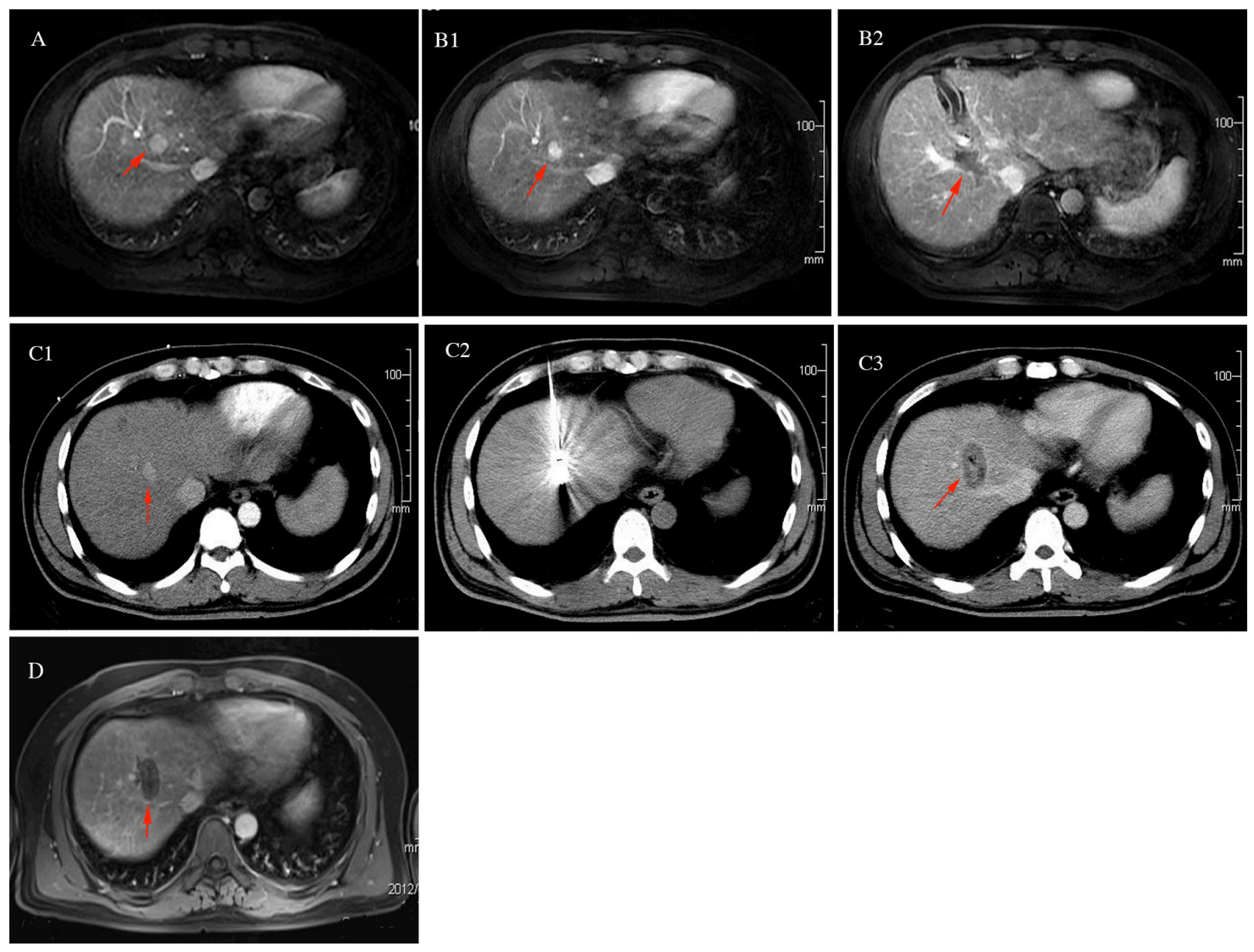

Figure 1: A 68-years-old male patient with primary liver S8 cancer underwent ultrasound-guided microwave ablation previously, but off-target effect appeared one month postoperatively. The patients thus underwent CT-guided microwave ablation (MWA) in our hospital. There was no indication of tumor residue or recurrence in the follow-ups. (A) The upper abdomen MRI indicated: liver S8 tumor with the diameter of $1.2 \mathrm{~cm}$ (red arrow); (B) Off-target phenomenon occurred after ultrasound-guided MWA: The upper abdomen MRI review: the liver S8 lesion was still there without any significant changes (B1, red arrow), but there was a type of round shaped and low signal area (B2, red arrow) beside the lesion. (C) CT-guided MWA for liver tumor near the diaphragm: C1: Contrastenhanced CT clearly manifested the liver S8 lesion (red arrow) before MWA. C2: MWA antenna precisely inserted into the tumor during the ablation process, with its needle tip slightly exceeded the edge of the tumor. C3: Contrast-enhanced CT immediately after MWA: ablation area completely covered the tumor (red arrow), without tumor residue. (D) The upper abdomen MRI review one month postoperatively: tumor achieved complete response without residue. 
which was significantly higher than our study. Regarding the treatment for liver tumors near the diaphragm, CTguided MWA through the lung had a higher CR rate and lower LR rate compared to ultrasound-guided MWA with artificial ascites or artificial pleural effusions.

Through group study, we showed that the efficacy of CT-guided MWA through the lung for liver tumors near the diaphragm was impacted by the diameter of the liver tumor. The efficacy of Group I (diameter $\leq 3.0 \mathrm{~cm}$ ) was significantly better than Group II (diameter $>3.0 \mathrm{~cm}$ ). The CR rate of Groups I and II were 99.0\% (100/101) and $80.0 \%(24 / 30)$, respectively $(\chi 2=16.525, P=0.001)$. The result was similar to the Head et al. [24] study of RFA for liver tumors near the diaphragm in which they found that the local progression of tumors $>3 \mathrm{~cm}$ in diameter was greater than tumors $<3 \mathrm{~cm}(70.6 \%$ vs. $12.5 \%)$. The following reasons explain why liver tumors $>3 \mathrm{~cm}$ in diameter have worse therapeutic efficacy. Indeed, it is difficult to achieve complete ablation with a one-time single antenna; multiple adjustments of the antenna are required for ablation, and it is difficult to set a reasonable ablation power and time to avoid residual tumor.

For the 117 patients with 131 liver tumors near the diaphragm in the current study, there were no fatal and disabling complications after CT-guided MWA through the lung. The total complication rate was $23.6 \%$, which was slightly higher than that reported for ultrasound-guided MWA [19-22]. This finding may be accounted for as follows: the puncture procedure cannot be shown in realtime under CT guidance, and it is heavily impacted by patient breathing activity. CT guidance cannot monitor the real-time ablation range of an ablation antenna. Of note, we could take several measures to reduce the complication rate. First, teach patients to do breathing exercises before MWA. Second, evaluate the path of blood vessels around the tumor and along the puncture path before MWA; contrast-enhanced CT is recommended when necessary. Third, a low power, an extended ablation time, an intense
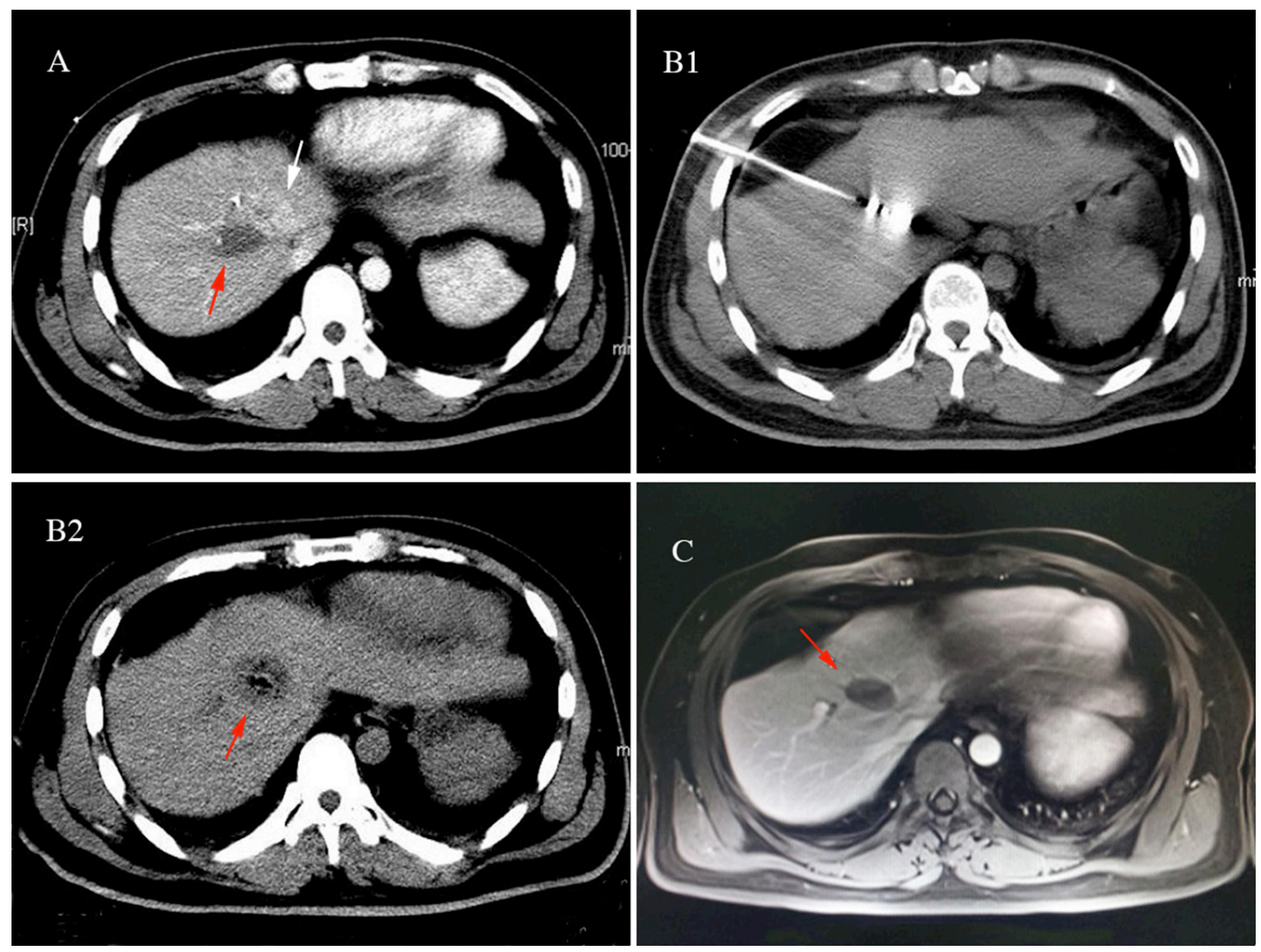

Figure 2: A 57-year-old female found a liver S8 metastatic tumor with diameter of $1.8 \mathrm{~cm} 2$ years after modified radical mastectomy of the left-side infiltrating ductal carcinoma received the ultrasound guided MWA. The postoperative review implied only a small portion of lesion was ablated, the patients experienced the partially off-target effect. The patients then underwent CT-guided microwave ablation (MWA) in our hospital. There was also no indication of tumor residue or recurrence in the follow-ups. (A) Partially off-target phenomenon occurred after ultrasound-guided MWA: The contrast-enhanced CT review: a small portion of the liver S8 lesion was ablated (white arrow), but there was a low-density area (red arrow) beside the lesion. (B) CT-guided MWA for liver tumor near the diaphragm: B1: MWA antenna precisely inserted into the tumor during the ablation process, with its needle tip slightly exceeded the edge of the tumor. B2: Contrast-enhanced CT immediately after MWA: ablation area completely covered the tumor (red arrow), without tumor residue. (C) The upper abdomen MRI review 2 months postoperatively: tumor achieved complete response without residue (red arrow). 
Table 2: The baseline information of all the patients

\begin{tabular}{lccc}
\hline Variables & Group I & Group II & P values \\
\cline { 2 - 3 } Sex (n) & $(\mathbf{n = 1 0 1 )}$ & $\mathbf{( n = 3 0 )}$ & 0.289 \\
female & 17 & & \\
male & 84 & 22 & 0.647 \\
Age (year) & $56.2 \pm 11.76$ & $59.0 \pm 10.32$ & 0.254 \\
Size (cm) & $1.76 \pm 0.61$ & $3.96 \pm 0.81$ & 0.051 \\
Diagnose & & & 14 \\
HCC & 69 & 16 & \\
Metastases & 32 & & \\
\hline
\end{tabular}

Values with " \pm ” are written as mean \pm SD; HCC: hepatocellular carcinoma.

The tumors were sorted to Group I if the size of the tumor was $<3.0 \mathrm{~cm}$ and the tumors were sorted to Group II if the size of the tumor was $\geq 3.0 \mathrm{~cm}$.

monitor, and a shortened scan interval are suggested to be applied for large liver tumors near the diaphragm. Fourth, pay attention to monitoring diaphragmatic thickening and pulmonary exudative changes. All of the complications in our study were minor. There were no complaints of significant discomfort and no treatment needed, and the patients were discharged after a 2-day intense observation period. Moreover, the most severe complications of WMA were injury to the neighboring dangerous organs [25-30]. In agreement with the study involving ultrasound-guided MWA with artificial ascites or artificial pleural effusions for liver tumors near the diaphragm [19-22], no severe complications occurred in our study. In subgroup analysis, the incidence of pneumothoraces was $15.3 \%$, which was significantly lower than the $45 \%(5 / 11)$ in the RFA study conducted by Shibata et al., the $37.5 \%(9 / 24)$ in the Kato et al. study [31], the $71.4 \%(5 / 7)$ in the Toyoda et al. study, [32] and the 45\% (17/38) in the Park et al. study [33]. CTguided MWA through the lung is a safe method, but the complication rate is significantly impacted by the size of liver tumors. The complication rate for liver tumors with a diameter $>3.0 \mathrm{~cm}$ was significantly greater than liver tumors $\leq 3.0 \mathrm{~cm}$ in diameter $(43.3 \%$ vs. $19.8 \%$; $\left.\left[\chi^{2}=6.796\right], P=0.015\right)$. All of the severe complications occurred in patients with liver tumors $>3.0 \mathrm{~cm}$ in diameter. For liver tumors with a relatively large diameter, multiple adjustments of the antenna are needed during MWA, which may lead to an increase in the rate of complications, such as the incidence of pneumothoraces in patients with liver tumors $>3.0 \mathrm{~cm}$ in diameter compared to liver tumors $\leq 3.0$ $\mathrm{cm}$ in diameter $(26.7 \%$ and $11.9 \%$, respectively; $[\chi 2=3.909]$, $P=0.048$ ). Several studies have reported that the incidence of pneumothoraces is associated with the length of the lung puncture path, number of punctures, emphysema, and other factors $[24,25]$. Longer ablation time and higher power were required to achieve complete ablation for larger tumors, which could also increase the ablation range and ablation-related complications.

Compared to the ultrasound-guided MWA assisted artificial pleural effusion or ascites for liver tumors near the diaphragm, CT-guided MWA had several advantages. First, CT guidance has a higher ablation success rate, with high repeatability. The success of ultrasound-guided MWA for liver tumors near the diaphragm depends on the establishment of an artificial pleural effusion or ascites; however, the technology of artificial pleural effusion or ascites relies heavily on the operator's experience and cannot ensure successful implementation for all patients, thus it would impact the next step of ablation. Rahim et al. [34], Song et al. [20] and Park et al. [22] reported that the success rate of artificial ascites was $88 \%, 90.9 \%$, and $86.7 \%$, respectively. Lin et al. [35] and Zhang et al. [23] reported that the success rate of artificial pleural effusion was $95.0 \%$ and $98.2 \%$, respectively. Moreover, for patients who underwent artificial pleural effusion or suffered from pleurisy and patients who underwent surgical resection of liver tumors, transarterial chemoembolization, hepatic tumor ablation, or had peritonitis, it is more difficult to establish artificial pleural effusion or ascites due to the peritoneal or pleural adhesions and normal anatomic position changes [20, 23, 34]. Therefore, ultrasoundguided artificial ascites and artificial pleural effusionassisted MWA for liver tumors near the diaphragm are difficult to repeat. Second, CT-guided MWA can clearly judge the ablation range, the degree of thickening of the diaphragm, and the leaking change of lung tissues near the diaphragm, therefore CT-guided MWA can directly determine the degree of damage to the diaphragm. During MWA, the thickening or coarse diaphragm indicates that the edge of the ablated thermal coagulation necrosis was close to the diaphragm, which would cause stress-induced edema of the diaphragm. An intra-operative CT scan that 
shows the right lower lung has a flake- or flocculent-shape dense shadow suggests that the heat generated during MWA passed through the diaphragm to the lung, leading to exudative changes. When the above phenomenon occurs, the ablation should be promptly stopped to avoid damage to the diaphragm. There were 22 patients with diaphragm thickening and 8 patients with pulmonary exudative changes, but none of the patients had significant complications after MWA. Due to interference of the gas generated in the process of liver tumor coagulation necrosis by ablation, ultrasound-guidance cannot clearly display the ablation range, the diaphragm, and the ablation reaction of lung tissue near the diaphragm. Third, all of the complications caused by CT-guided MWA through the lung are controllable and treatable. It took 1-2 weeks for patients to completely absorb the pleural effusion and ascites after the artificial pleural effusion and artificial ascites were established. Moreover, artificial pleural effusion requires chest tube placement for persistent drainage $[19,34]$, resulting in a greater impact on the treatment and life of patients.

There were some limitations to this study. First, the study was a single-center regression analysis; a multicenter, multi-case, and long-term follow-up to evaluate the efficacy and safety of CT-guided MWA through the lung for liver tumors near the diaphragm is warranted. Second, selection bias was possible because there was a large difference in the number of patients between the group with intra-hepatic tumor diameters $<3 \mathrm{~cm}$ and the group with tumor diameters $\geq 3 \mathrm{~cm}$. Despite the limitations, these results may contribute to guiding the MWA ablation treatment of liver tumors near the diaphragm.

\section{MATERIALS AND METHODS}

\section{Patients}

A retrospective study was conducted involving 131 liver tumors that were close to the diaphragm in 117 patients who underwent CT-guided MWA between January 2011 and July 2014. The study was approved by the Institutional Review Board of Sun Yat-sen University Cancer Center. Written informed consent was obtained from all patients before therapy. The patient inclusion criteria consisted of the following: (1) single hepatic tumor with a diameter $\leq 6 \mathrm{~cm}$, or multiple hepatic tumors with the largest diameter $\leq 3 \mathrm{~cm}$ and tumor number $\leq 3$; (2) good general condition, Karnofsky scale (KPS) $\geq 70$; Eastern Cooperative Oncology Group Performance Status score: $0-1$; (3) class A or B Child-Pugh score for liver function; and (4) a platelet count $>50 \times 10^{9} / \mathrm{L}$, a neutrophil count $>2 \times 10^{9} / \mathrm{L}$, an international normalized thrombin time ratio $>1.5$, and a haemoglobin $(\mathrm{HGB}) \geq 100 \mathrm{~g} / \mathrm{L}$. Of the 117 patients, there were 91 males and 26 females; the average age was $57.4 \pm 11.4$ years (range, 25-79 years). One hundred two patients had single liver tumors close to the diaphragm, 13 patients had 2 liver tumors close to the diaphragm, and 1 patient had 3 liver tumors close to the diaphragm. The average tumor diameter was $2.27 \pm 1.14$ $\mathrm{cm}$ (range, 0.6-6.0 cm). Forty-eight liver metastases and 83 primary liver tumors were included. All patients with liver metastases were pathologically-confirmed, and the primary tumors were all under control by surgery. The diagnosis for patients with primary liver tumors all met American Association for the Study of Liver Diseases (AASLD) criteria. The tumors were sorted based on size. The tumors were sorted to Group I if the size of the tumor was $<3.0 \mathrm{~cm}$ ( $\mathrm{n}=101$ tumors) and the tumors were sorted to Group II if the size of the tumor was $\geq 3.0 \mathrm{~cm} \mathrm{(} \mathrm{n}=30$ tumors). The baseline information of patients was shown in Table 2.

\section{Microwave ablation}

All patients underwent contrast-enhanced CT or MRI scan 2 weeks before surgery to determine the size and location of the tumors. During treatment, CT was used to locate the liver tumors (PHILIPS 16-slice spiral CT [90-cm pore size and 5-mm scanning thickness]; The Netherlands) and to design the optimal puncture needle route. Routine disinfection and local anaesthesia was applied around the puncture point, and a $16 \mathrm{G}$ microwave antenna was inserted gradually into the tumor along the pre-determined angle. The entire MWA procedure treatment was conducted with intravenous anaesthesia (propofol [1.5 4.5 $\mathrm{mg} / \mathrm{kg}$ continuous intravenous infusion/h]; AstraZeneca S.p.A., Italy) and under realtime ECG monitoring. The setting of the MWA parameters depended on the manufacturer's recommendation and our experience. The ablation area must completely cover the tumor and exceed the tumor edge to approximately $0.5 \mathrm{~cm}$. Chest and upper abdominal CT scans were obtained out immediately post-operatively to evaluate whether or not the ablation area was sufficient, and whether or not there were complications, such as bleeding and a pneumothorax. Routine blood testing, biochemical testing, and chest X-rays were carried out the first day after MWA treatment. If the related examination results showed no abnormalities and the patient was recovering satisfactorily, the patient was discharged the following day. One hundred seventeen patients with 131 liver tumors close to the diaphragm all successfully underwent CT-guided MWA through the lung.

MWA equipment: A microwave delivery system (FORSEA; Qinghai Microwave Electronic Institute, Nanjing, China) was used in the studies. This system consisted of a MTC-3 microwave generator (FORSEA) with a frequency of $2450 \mathrm{MHz}$, a power output of 10-150 $\mathrm{W}$, a flexible low-loss cable, and a 16-gauge cooled-shaft antenna.

\section{Follow-ups}

Upper abdominal contrast-enhanced CT or MRI scans were carried out every month for the first 3 months 
post-operatively. If no tumor residue or tumor recurrence was detected, a re-examination was carried out every 3-6 months (CT: HiSpeed or LightSpeed QX/i, GE Medical Systems; Milwaukee, WI; contrast agent: Ultravist 300 [injection speed was fixed as $3 \mathrm{ml} / \mathrm{s}$ ]; Schering, Berlin, Germany; MRI: Discovery MR750 3.0T; GE Medical Systems; contrast agent: Gd-DTPA [injection speed was fixed to $3 \mathrm{ml} / \mathrm{s}$ ]; GE Healthcare, IDA Business Park Carrigtohill, Ireland).

\section{Therapeutic efficacy and complication assessment}

\section{Therapeutic efficacy evaluation}

(1) A complete response (CR; Figure 1) was defined as tumor ablation area that did not show enhanced lesions on the follow-up liver CT/MRI scan. (2) An incomplete response (ICR) or "tumor residue" was defined as a residual enhanced lesion in the tumor ablation area on the follow-up liver CT/MRI scan. (3) A local recurrence (LR) was defined as a CR on the first month follow-up CT/MRI scan, but an enhanced area inside or at the edge of the ablation area on subsequent review.

\section{Complications}

Severe complications included complications which appeared within 2 weeks following MWA, and if no treatments were given to patients, could cause prolonged hospitalization, an increased disability rate, or death. All other complications were defined as mild.

It is worth noting that congestive edema of the diaphragm and mild right lung exudative change during the MWA treatment process are the only stress response to MWA, and were not considered to be complications. Congestive edema of the diaphragm was defined as diaphragmatic thickening or coarse-like changes on the CT obtained immediately after ablation. A mild right lung exudative change was defined as a flake- or flocculentshape dense shadow in the lung.

\section{Statistical analysis}

SPSS for OS X (version 20.0; SPSS, Inc., Chicago, IL, USA) was used for statistical analysis. Intergroup $t$ tests were used for quantitative data, and intergroup $\chi^{2}$ tests were used for count data. A $P<0.05$ was considered statistically significant.

\section{CONCLUSIONS}

CT-guided MWA through the lung for treating liver tumors has the advantages of clear imaging, accurate positioning, and accurate puncture into the liver tumors near the diaphragm. CT-guided MWA can clearly monitor the changes in the diaphragm and the lung tissues near the diaphragm during the ablation process. CT-guided
MWA can also make up some of the defects of ultrasoundguided MWA with good therapeutic efficacy. Furthermore, all of the complications that occurred during ablation are treatable. Thus, CT-guided MWA through the lung plays an important role in treating liver tumors near the diaphragm.

\section{Author contributions}

Weijun Fan have made substantial contributions to conception and design and agree to be accountable for all aspects of the work in ensuring that questions related to the accuracy or integrity of any part of the work are appropriately investigated and resolved. Han Qi, Hao Zhang, Liang Zhang, Chao Wan and Ze Song have acquisition of data, analysis and interpretation of data; Han Qi have been involved in drafting the manuscript and revising it critically for important intellectual content; Han Qi have given final approval of the version to be published. Each author have participated sufficiently in the work to take public responsibility for appropriate portions of the content.

\section{Ethics and consent}

The study was approved by the Institutional Review Board of Sun Yat-sen University Cancer Center. Written informed consent was obtained from all patients before therapy.

\section{ACKNOWLEDGMENTS}

A brief acknowledgment of grants: Project supported by the National Natural Science Foundation of China (Grant No.81371651).

\section{CONFLICTS OF INTEREST}

The authors indicated no potential conflicts of interest.

\section{REFERENCES}

1. Ryan TP, Turner PF, Hamilton B. Interstitial microwave transition from hyperthermia to ablation: historical perspectives and current trends in thermal therapy. Int $\mathrm{J}$ Hyperthermia. 2010; 26:415-33.

2. Ahmed M, Solbiati L, Brace CL, Breen DJ, Callstrom MR, Charboneau JW, Chen MH, Choi BI, de Baère T, Dodd GD 3rd, Dupuy DE, Gervais DA, Gianfelice D, et $\mathrm{al}$, and International Working Group on Image-guided Tumor Ablation, and Interventional Oncology Sans Frontières Expert Panel, and Technology Assessment Committee of the Society of Interventional Radiology, and Standard of Practice Committee of the Cardiovascular 
and Interventional Radiological Society of Europe. Imageguided tumor ablation: standardization of terminology and reporting criteria - a 10-year update. Radiology. 2014; 273:241-60.

3. Ren H, Liang P, Yu X, Wang Y, Lu T, Li X. Treatment of liver tumours adjacent to hepatic hilum with percutaneous microwave ablation combined with ethanol injection: a pilot study. Int J Hyperthermia. 2011; 27:249-54.

4. Jansen MC, van Hillegersberg R, Chamuleau RA, van Delden OM, Gouma DJ, van Gulik TM. Outcome of regional and local ablative therapies for hepatocellular carcinoma: a collective review. Eur J Surg Oncol. 2005; 31:331-47.

5. Kang TW, Rhim H, Kim EY, Kim YS, Choi D, Lee WJ, Lim HK. Percutaneous radiofrequency ablation for the hepatocellular carcinoma abutting the diaphragm: assessment of safety and therapeutic efficacy. Korean J Radiol. 2009; 10:34-42.

6. Omata M, Tateishi R, Yoshida H, Shiina S. Treatment of hepatocellular carcinoma by percutaneous tumor ablation methods: ethanol injection therapy and radiofrequency ablation. Gastroenterology. 2004; 127:S159-66.

7. Tateishi R, Shiina S, Teratani T, Obi S, Sato S, Koike Y, Fujishima T, Yoshida H, Kawabe T, Omata M. Percutaneous radiofrequency ablation for hepatocellular carcinoma. An analysis of 1000 cases. Cancer. 2005; 103:1201-09.

8. Choi D, Lim HK, Rhim H, Kim YS, Lee WJ, Paik SW, Koh KC, Lee JH, Choi MS, Yoo BC. Percutaneous radiofrequency ablation for early-stage hepatocellular carcinoma as a first-line treatment: long-term results and prognostic factors in a large single-institution series. Eur Radiol. 2007; 17:684-92.

9. Kondo Y, Yoshida H, Shiina S, Tateishi R, Teratani T, Omata M. Artificial ascites technique for percutaneous radiofrequency ablation of liver cancer adjacent to the gastrointestinal tract. Br J Surg. 2006; 93:1277-82.

10. Koda M, Ueki M, Maeda N, Murawaki Y. Diaphragmatic perforation and hernia after hepatic radiofrequency ablation. AJR Am J Roentgenol. 2003; 180:1561-62.

11. Rhim H. Complications of radiofrequency ablation in hepatocellular carcinoma. Abdom Imaging. 2005; 30:409-18.

12. Rhim H, Dodd GD 3rd, Chintapalli KN, Wood BJ, Dupuy DE, Hvizda JL, Sewell PE, Goldberg SN. Radiofrequency thermal ablation of abdominal tumors: lessons learned from complications. Radiographics. 2004; 24:41-52.

13. Ikeda M, Okada S, Ueno H, Okusaka T, Kuriyama H. Radiofrequency ablation and percutaneous ethanol injection in patients with small hepatocellular carcinoma: a comparative study. Jpn J Clin Oncol. 2001; 31:322-26.

14. Ward J, Robinson PJ. How to detect hepatocellular carcinoma in cirrhosis. Eur Radiol. 2002; 12:2258-72.

15. Liang P, Dong B, Yu X, Yu D, Wang Y, Feng L, Xiao Q. Prognostic factors for survival in patients with hepatocellular carcinoma after percutaneous microwave ablation. Radiology. 2005; 235:299-307.

16. Lencioni R, Cioni D, Crocetti L, Franchini C, Pina CD, Lera J, Bartolozzi C. Early-stage hepatocellular carcinoma in patients with cirrhosis: long-term results of percutaneous image-guided radiofrequency ablation. Radiology. 2005; 234:961-67.

17. Shimada S, Hirota M, Beppu T, Shiomori K, Marutsuka T, Matsuo A, Tanaka E, Ogawa M. A new procedure of percutaneous microwave coagulation therapy under artificial hydrothorax for patients with liver tumors in the hepatic dome. Surg Today. 2001; 31:40-44.

18. Ohmoto K, Tsuzuki M, Yamamoto S. Percutaneous microwave coagulation therapy with intraperitoneal saline infusion for hepatocellular carcinoma in the hepatic dome. AJR Am J Roentgenol. 1999; 172:65-66.

19. Koda M, Ueki M, Maeda Y, Mimura K, Okamoto K, Matsunaga Y, Kawakami M, Hosho K, Murawaki Y. Percutaneous sonographically guided radiofrequency ablation with artificial pleural effusion for hepatocellular carcinoma located under the diaphragm. AJR Am J Roentgenol. 2004; 183:583-88.

20. Song I, Rhim H, Lim HK, Kim YS, Choi D. Percutaneous radiofrequency ablation of hepatocellular carcinoma abutting the diaphragm and gastrointestinal tracts with the use of artificial ascites: safety and technical efficacy in 143 patients. Eur Radiol. 2009; 19:2630-40.

21. Park SY, Tak WY, Jeon SW, Cho CM, Kweon YO, Kim SK, Choi YH. The efficacy of intraperitoneal saline infusion for percutaneous radiofrequency ablation for hepatocellular carcinoma. Eur J Radiol. 2010; 74:536-40.

22. Nam SY, Rhim H, Kang TW, Lee MW, Kim YS, Choi D, Lee WJ, Park Y, Chang I, Lim HK. Percutaneous radiofrequency ablation for hepatic tumors abutting the diaphragm: clinical assessment of the heat-sink effect of artificial ascites. AJR Am J Roentgenol. 2010; 194:W227-31.

23. Zhang D, Liang P, Yu X, Cheng Z, Han Z, Yu J, Liu F. The value of artificial pleural effusion for percutaneous microwave ablation of liver tumour in the hepatic dome: a retrospective case-control study. Int J Hyperthermia. 2013; 29:663-70.

24. Head HW, Dodd GD 3rd, Dalrymple NC, Prasad SR, El-Merhi FM, Freckleton MW, Hubbard LG. Percutaneous radiofrequency ablation of hepatic tumors against the diaphragm: frequency of diaphragmatic injury. Radiology. 2007; 243:877-84.

25. Chopra S, Dodd GD 3rd, Chanin MP, Chintapalli KN. Radiofrequency ablation of hepatic tumors adjacent to the gallbladder: feasibility and safety. AJR Am J Roentgenol. 2003; 180:697-701.

26. Kang TW, Rhim H, Lee MW, Kim YS, Choi D, Lee WJ, Lim HK. Radiofrequency ablation for hepatocellular carcinoma abutting the diaphragm: comparison of effects 
of thermal protection and therapeutic efficacy. AJR Am J Roentgenol. 2011; 196:907-13.

27. Levit E, Bruners P, Günther RW, Mahnken AH. Bile aspiration and hydrodissection to prevent complications in hepatic RFA close to the gallbladder. Acta Radiol. 2012; 53:1045-48.

28. Li M, Yu XL, Liang P, Liu F, Dong B, Zhou P. Percutaneous microwave ablation for liver cancer adjacent to the diaphragm. Int J Hyperthermia. 2012; 28:218-26.

29. Zhou P, Liang P, Yu X, Wang Y, Dong B. Percutaneous microwave ablation of liver cancer adjacent to the gastrointestinal tract. J Gastrointest Surg. 2009; 13:318-24.

30. Shibata T, Shibata T, Maetani Y, Kubo T, Itoh K, Togashi $\mathrm{K}$, Hiraoka M. Transthoracic percutaneous radiofrequency ablation for liver tumors in the hepatic dome. J Vasc Interv Radiol. 2004; 15:1323-27.

31. Kato T, Yamagami T, Hirota T, Matsumoto T, Yoshimatsu R, Nishimura T. Transpulmonary radiofrequency ablation for hepatocellular carcinoma under realtime computed tomography-fluoroscopic guidance. Hepatogastroenterology. 2008; 55:1450-53.

32. Toyoda M, Kakizaki S, Horiuchi K, Katakai K, Sohara N, Sato K, Takagi H, Mori M, Nakajima T. Computed tomography-guided transpulmonary radiofrequency ablation for hepatocellular carcinoma located in hepatic dome. World J Gastroenterol. 2006; 12:608-11.

33. Park BJ, Byun JH, Jin YH, Won HJ, Shin YM, Kim KW, Park SJ, Kim PN. CT-guided radiofrequency ablation for hepatocellular carcinomas that were undetectable at US: therapeutic effectiveness and safety. J Vasc Interv Radiol. 2009; 20:490-99.

34. Rhim H, Lim HK. Radiofrequency ablation for hepatocellular carcinoma abutting the diaphragm: the value of artificial ascites. Abdom Imaging. 2009; 34:371-80.

35. Liu LN, Xu HX, Lu MD, Xie XY. Percutaneous ultrasoundguided thermal ablation for liver tumor with artificial pleural effusion or ascites. Chin J Cancer. 2010; 29:830-35. 